\title{
Penerapan Kontroler PID pada Sistem Kendali Level Cairan dengan Metode Ziegler-Nichols Berbasis Arduino
}

\author{
Tari Pujiati1 ${ }^{1}$ Risfendra ${ }^{2}$ \\ 1.2UniversitasNegeriPadang \\ Jl.Prof.Dr.HamkaAirTawarPadang \\ Tarifujiatitf@gmail.com ${ }^{1}$,Risfendra@ft.unp.ac.id ${ }^{2}$
}

\begin{abstract}
Currently the use of PID control is widely used in the industrial world, as well as this design implemented in liquid level plants. The purpose of this research is to design a PID control system based on Arduin by applying it to a miniature fluid level control system design. Controls are used to keep the liquid state constant orr stable. The tank used is tubular with a capacity of 4 liters of liquid. The PID control design was carried out using the Ziegler-Nichols type-1 tuning method. Following the rules of this method, to obtain PID control parameters, two tuning experiments were carried out and obtained a constant or stable state in the second experiment, namely $\mathrm{Kp}=59,2 ; \mathrm{Ki}=98,7 ; \mathrm{Kd}=8,88$. In implementing the fluid control design, the liquid is fed into tank using a DC pump. The state of the liquid level in the tank measured using a potentiometer sensor equipped with a float. The result of controlling the level of fluid using PID control showed good performance, undershoot occurred when given a disturbance, namely $0,4 \mathrm{~cm}$ from the setpoint value for 2,4 seconds.
\end{abstract}

\section{Keywords-PID Control , Ziegler-Nichols, Potentiometer, Arduino}

Abstrak - Saat ini penggunaan kendali PID sangat banyak digunakan dalam dunia industri, demikian juga perancangan ini diimplementasikan pada plant level ketinggian cairan. Tujuan penelitian ini merancang bangun sistem kendali PID berbasis Arduino dengan mengaplikasikannya pada miniatur rancangan sistem kendali level ketinggian cairan. Kendali digunakan untuk menjaga keadaan cairan tetap konstan atau stabil. Tangki yang digunakan berbentuk tabung dengan kapasitas dapat menampung 4 liter cairan. Perancangan kendali PID dilakukan dengan metode penalaan Ziegler-Nichols tipe-1. Mengikuti aturan metode ini untuk mendapatkan parameter kendali PID dilakukan dua kali percobaan tuning dan mendapatkan keadaan konstan atau stabil pada percobaan kedua yaitu sebesar $\mathrm{Kp}=59,2$; Ki=98,7; Kd=8,88. Pada implementasi rancangan kendali cairan, cairan dimasukan ke dalam tangki menggunakan pompa DC. Keadaan level ketinggian cairan dalam tangki diukur menggunakan sensor Potensiometer yang dilengkapi dengan pelampung. Hasil dari pengendalian level ketinggian cairan menggunakan kendali PID menunjukkan kinerja yang baik, undershoot terjadi saat diberi gangguan yaitu 0,4 cm dari nilai setpoint selama 2,4 detik.

Kata kunci-Kendali PID, Ziegler-Nichols, Potensiometer, Arduino

\section{Pendahuluan}

Pengendali PID sangat banyak penggunaannya dalam dunia industri pada dalam beberapa tahun belakangan ini, dengan hasil tanggapan yang sangat cepat tetapi terjadi Overshoot yang sangat besar juga [1]. Demikian pula dengan mengaplikasikan kendali PID Klasik pada level ketinggian cairan. Paramater kendali PID biasanya bernilai tetap selama selama operasi atau proses berlangsung, konsekuensinya pada pengendali ini menjadi tidak efektif mengendalikan sistem jika terjadi gangguan yang tidak diketahui atau perubahan sekitar[2]. Jadi kendali PID menjadi tidak cukup adaptif [3] serta penentuan parameter PID juga sangat sulit dimengerti dan dilakukan[1]. Salah satu cara mendapatkan nilai dari parameter PID dengan menggunakan metode tipe-1 Ziegler-Nichols open loop.

Pada penelitian sistem kendali cairan menggunakan Kontroler PID. Kendali PID adalah salah satu metoda yang umum digunakan di industri karena memiliki nilai presisi yang cukup tinggi, mudah diaplikasikan dan handal [4]. Pengendalian dilakukan dengan mengurangi sinyal kesalahan pada saat sistem bekerja, serta mampu memberikan keluaran sinyal yang memiliki respon yang cepat, error kecil, dan meminimalisir terjadinya 
overshoot[5]. Semakin kecil nilai error yang terjadi maka semakin lancar unjuk kerja sistem kendali yang digunakan. Kontroler ini mempunyai nilai parameter proporsional sebagai nilai pengali error untuk nilai perbaikan. Nilai parameter integral sebagai pelurusan kekeliruan steady state mencapai nol. Nilai standar diferensial sebagai perbaikan respon trasien dan meredam osilasi[6]. Dalam menentukan nilai dari parameter PID tersebut dapat menggunakan beberapa metoda, salah satunya memakai metoda Ziegler-Nichols tipe 1.

Kendali PID mempunyai balasan yang cepat dan mencapai respon steady state error nol. Keluaran sinyal kendali PID dirumusukan pada [7]:

$$
\mathrm{u}(\mathrm{t})=\mathrm{Kp} \cdot \mathrm{e}(\mathrm{t})+\mathrm{Ki} \cdot \int_{0}^{t} e(t)+\mathrm{Kd} \cdot \mathrm{de}(\mathrm{t}) / \mathrm{dt}
$$

Dalam area waktu disktrik maka keluaran sinyak kendali dirumuskan :

$u(k)=K p .(e(k))+K i . T s[e(k-1)+e(k)]+K d . e(k)-e(k-1) / T$

Keterangan :

$\mathrm{u}(\mathrm{k})=$ Sinyal Keluaran

$\mathrm{Kp}=$ Konstanta Proporsional

$\mathrm{Ki}=$ Konstanta Integral

$\mathrm{Kd}=$ Konstanta Derivatif

Ts = Time Sampling

$\mathrm{e}(\mathrm{k})=$ Eror

Menyelesaikan parameter kendali PID untuk plant yang tidak diketahui model matematiknya dapat menggunakan metode tuning Ziegler-Nichols[10]. Untuk level ketinggian cairan plant terdiri dari sebuah motor pompa DC yang digunakan untuk memindahkan cairan dari tangki 1 ke tangki 2 dengan metode Ziegler-Nichols dapat digunakan.[8] metode ini adalah metode perdana dari Ziegler-Nichols untuk penalaan kendali PID, dengan melakukan percobaan secara eksperimen penerimaan plant terhadap masukan unit-step akan menimbulkan kurva S seperti gambar 1. Kurva berbentuk S mempunyai karekteristik dengan memiliki dua buah parameter, yaitu waktu tunda L dan konstanta waktu T[9]. Kedua parameter tersebut didapatkan dengan menggambar garis tangensial pada titik infleksi kurva S untuk menghasilkan perpotongan garis tangensial dengan garis axis waktu dan garis $\mathrm{c}(\mathrm{t})=\mathrm{K}$ seperti gambar 2 .

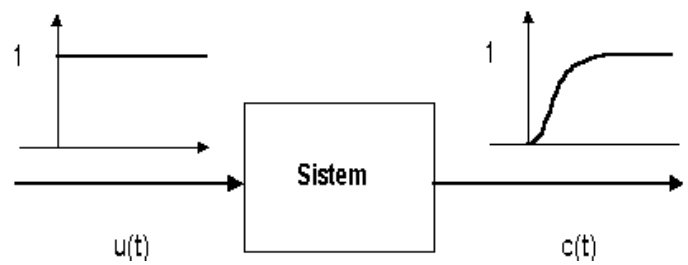

Gambar 1. Tanggapan Unit-Step $c(t)$

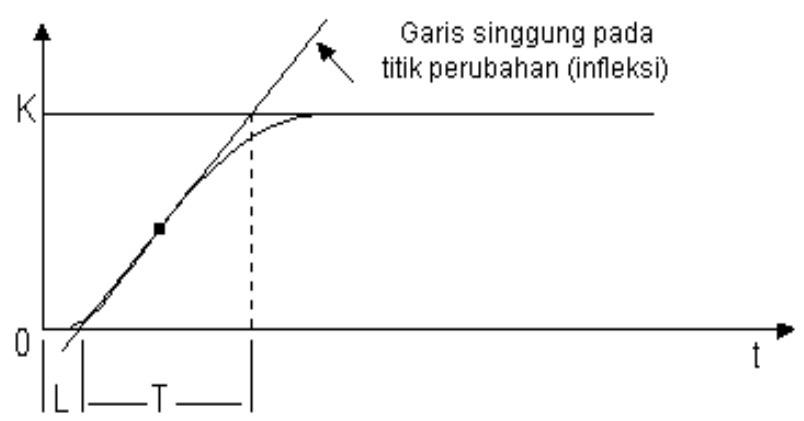

Gambar 2. Tanggapan Kurva $S$

Bersumber pada kurva $S$ dapat menetapkan parameter dari Kp, Ki dan Kd dengan aturan pada tabel 1.

Tabel 1. Aturan Tuning Ziegler-Nichols tipe-1

\begin{tabular}{|c|c|c|c|c|c|}
\hline $\begin{array}{c}\text { Tipe } \\
\text { Konttroler }\end{array}$ & Kp & Ti & Td & Ki & Kd \\
\hline P & T/L & $\infty$ & 0 & & \\
\hline PI & $\begin{array}{c}0,9 \\
\text { T/L }\end{array}$ & L/0,5 & & & \\
\hline PID & $\begin{array}{c}1,2 \\
\text { T/L }\end{array}$ & 2L & $0,5 \mathrm{~L}$ & Kp/Ti & Kp.Td \\
\hline
\end{tabular}

\section{METODE}

Metode ini terdiri dari perancangan hardware dan perancangan software. Untuk perancangan hardware menggunakan Arduino Uno sebagai pengendali terpusat, Potensiometer (bola plastik sebagai pelampung) sebagai sensor level, Motor Pompa DC $12 \mathrm{v}$ sebagai plant memindahkan cairan dari tangki tangki 1 ke tangki 2 . Komponen ini dirancang bangun menjadi sistem kendali PID. Perancangan software menggunakan Arduino IDE dengan bahasa pemograman C.

Miniatur atau prototype level ketinggian cairan menggunakan motor pompa dc 12 volt sebagai penggerak air masuk menuju tangki 2. Perangkat lunak yang digunakan untuk mengolah data dan menampilkan grafik adalah Visual Basic.

Tangki yang digunakan untuk ketinggian level cairan berbentuk tabung berukuran 4 liter dengan keluaran cairan terdapat kran yang diset secara manual untuk menganalogikakan ouput. Berikut bentuk rancang bangun level ketinggian cairan dapat dilihat pada Gambar 4 dan 7.

\section{A. Blok diagram}

Diagram blok sistem merupakan salah satu elemen terpenting dalam perancangan dan pembuatan alat, sebab dari diagram bisa mengetahui prinsip kerja keseluruhan alat. Selain itu tujuannya yaitu menyederhanakan 
prosedur perancangan dan pembuatan pada masingmasing rangkaian, kemudian akan membentuk suatu sistem yang sesuai dengan perancangan. Secara garis besar prinsip kerja dari sistem yang dibuat ini seperti gambar 3.

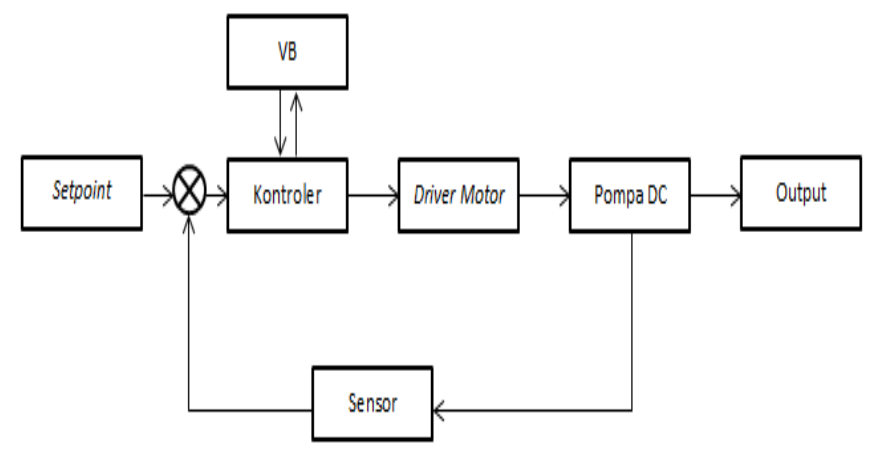

Gambar 3. Blok diagram

Penjelasan gambar 3 pada blok diagram diatas:

1. Setpoint merupakan input dari sistem yang akan dikendalikan. Setpoint yang diberikan yaitu nilai ketinggian level cairan yang diinginkan

2. Kontroler merupakan pusat kendali dari sistem dengan menggunakan mikrokontroler Arduino Uno.

3. Driver Motor digunakan untuk penghubung antara motor pompa DC dengan Arduino Uno

4. Pompa Dc digunakan sebagai aktuator atau penggerak masuknya cairan kedalam tangki

5. Sensor yang digunakan sebagai sensor pendeteksi ketinggian level cairan dalam tangki yaitu Potensiometer

6. VB (Visual Basic) digunakan sebagai media untuk mengontrol dan memonitoring sistem yang ditampilkan pada PC

\section{B. Perancangan Hardware}

\section{Perancangan Mekanik}

Perancangan ini bertujuan menyederhanakan juga mengurangi tingkat kesalahan dalam membuat Hardware dengan hasil yang optimal. Pembuatan rancangan mekanik dilakukan dengan menggunakan software SketchUp. Pembuatan mekanik alat ini menggunakan bahan akrilik dengan ketebalan $2 \mathrm{~mm}$ digunakan sebagai kerangka dari komponen yang digunakan. Pada perancangan tedapat dua buah tangki dalam bentuk dan ukuran yang berbeda. Tangki 1 digunakan sebagai tangki yang akan digunakan sebagai wadah kendali level ketinggian cairan yang dapat digunakan karena dilengkapi dengan satu buah kran. Selanjutnya tangki 2 berguna sebagau bak penampung air yang dikeluarkan dan yang akan diambil dari pompa dc yang digunakan. Berikut adalah rancangan Mekanik pada gambar 4.

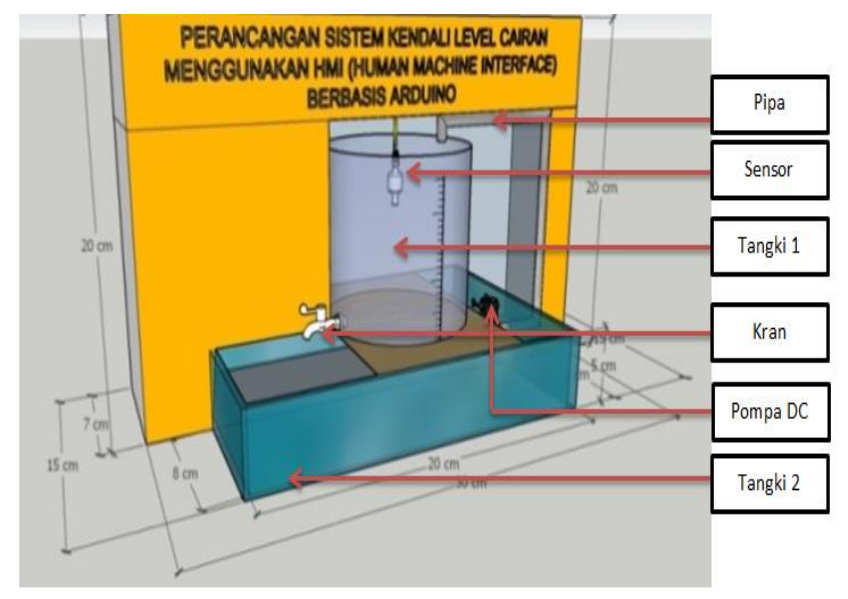

Gambar 4. Perancangan Mekanik

\section{Perancangan Rangkaian Elektronika}

Pada rangkaian elektronika, terdapat komponen yang digunakan yaitu, power suplay sebagai penurun tegangan untuk menjadi tegangan masukan dari step down converter, lalu tegangan dari step down converter diturunkan lagi untuk menjadi tegangan masukan mikrokontroler yang sebagai pusat kontrol sistem dihubungkan ke sensor Potensiometer, Driver Motor, motor Pompa 12v dan Software Visual Basic pada PC.

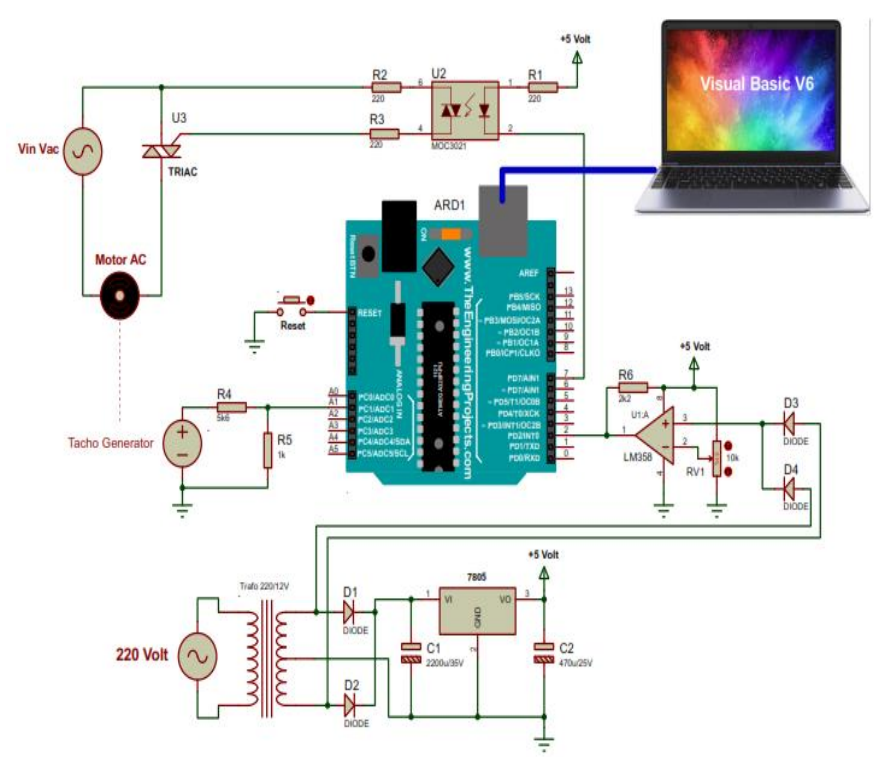

Gambar 5. Rangkaian Keseluruhan

\section{Perancangan Software}

Perancangan ini menggunakan software arduino IDE dengan bahasa pemograman C. Perancangan media untuk mengontrol dan memonitoring dilakukan dengan menggunakan software Visual Basic dengan menggunakan bahasa pemograman IDE visual. Untuk 
menjalankan alat dimulai dengan mendesain flowchart sistem dari program yang akan dibuat.

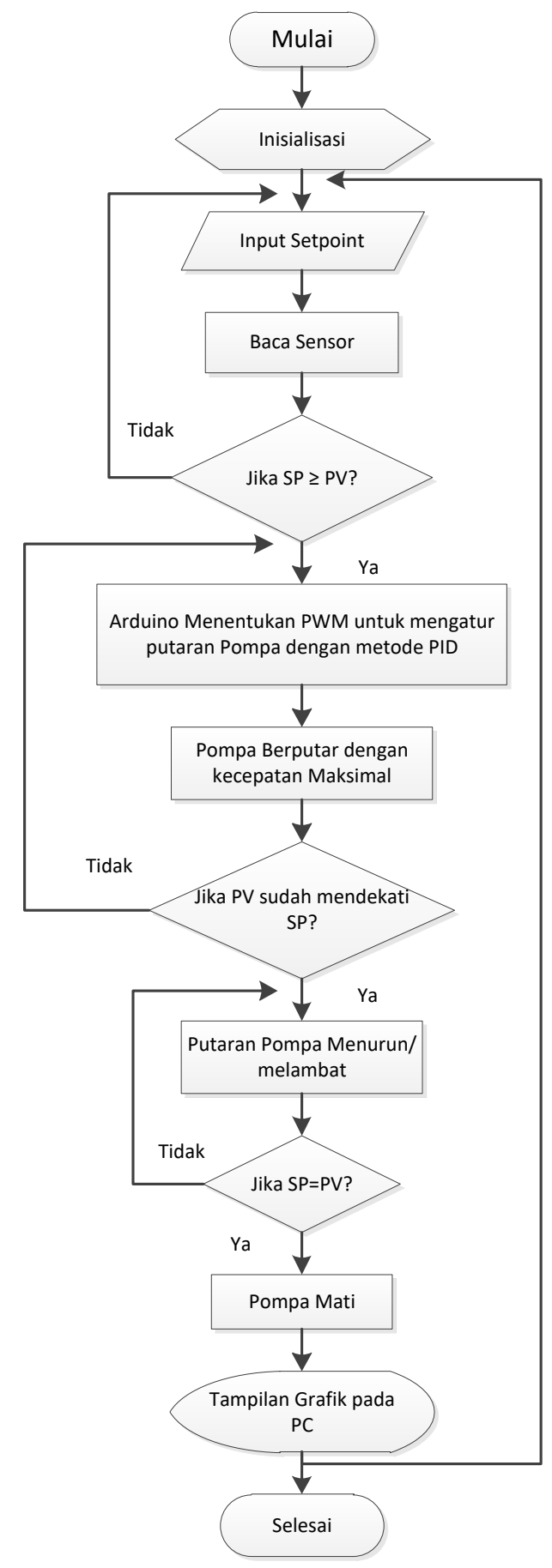

\section{Gambar 6. Flowchart Sistem Kendali Level Cairan}

Perancangan Flowchart merupakan perancangan logika atau urutan instruksi pemograman. Diagram alur dari suatu perancangan ditunjukan secara jelas dalam suatu algoritma yaitu bagaimana rencana aktualisasi tindakan. Perancangan Flowchart sistem dilakukan untuk mempermudah suatu perancangan software yang akan dibuat dengan melihat logika yang akan digunakan sebagai penjelasan dari urutan program yang digunakan pada perancangan alat tersebut.

\section{HASIL DAN PEMBAHASAN}

Pengujian ini dilakukan bertujuan mengamati apakah rancangan tersebut berjalan dengan baik atau tidak. Untuk melakukan pengujian alat ini dengan menggunakan catu daya yang telah dipasang pada alat, mikrokontroler Arduino Uno, Potensiometer, motor pompa $12 \mathrm{v}$ dan pc digunakan untuk menampilkan grafik keluaran dari proses yang dilakukan. Berikut adalah rancangan alat yang sudah dibuat dengan mengunakan akrilik sebagai kerangka rancangan.

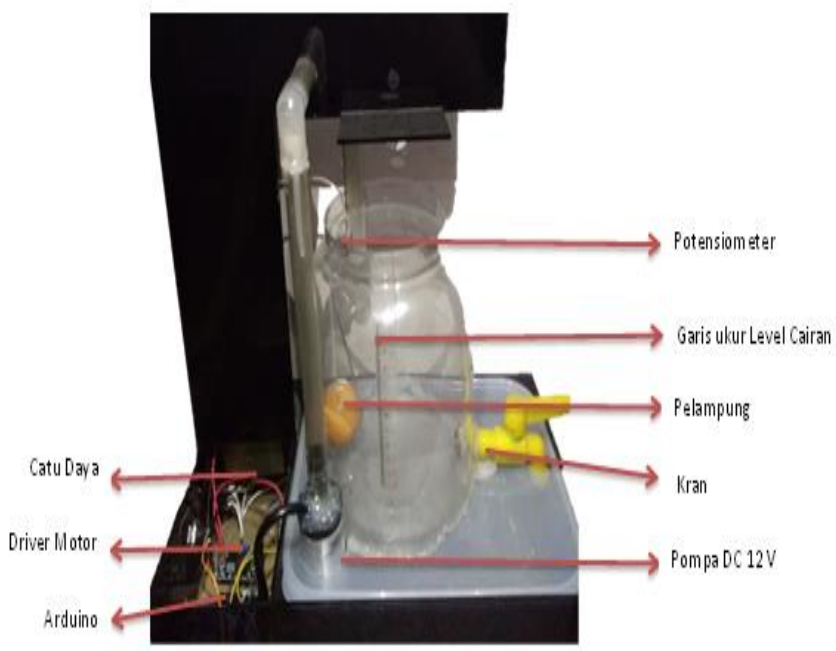

\section{Gambar 7. Prototype Sistem Kendali Level Cairan}

Langkah Pertama yang harus dilakukan untuk mengaktifkan rancangan ini yaitu hubungkan alat pada sumber 220 Volt. Kemudian hidupkan alat dengan memencet saklar on/off alat. Setelah alat hidup maka lakukan pegujian alat yang diinginkan pada tampilan PC. Terdapat beberapa pengujian yang dilakukan yaitu Pengujian pertama yang dilakukan Tuning parameter PID, Pengujian nilai setpoint yang ditetapkan tanpa gangguan dan Pengujian nilai setpoint dengan diberi gangguan buka kran.

\section{Pengujian Tuning Parameter PID}

Pengujian Tuning Respon PID ini dilakukan untuk mendapatkan nilai $\mathrm{Kp}$, Ki dan $\mathrm{Kd}$ supaya pergerakan pompa berisolasi sekecil mungkin saat diberi nilai Setpoint. Setpoint berupa nilai level tinggi cairan yang diset pada software Arduino yang dapat juga ditentukan melalui tampilan pada PC melalui Aplikasi Visual Basic.

Dalam menentukan parameter PID dengan metode Ziegler-Nichols tipe-1. Dengan menggunakan 
aturan dan rumus dari metoda ini terdapat pada table 1.Penentuan penalaan Parameter PID dilakukan dengan dua kali percobaan untuk mendapatkan nilai yang stabil dalam mengendalikan sistem.

a. Percobaan Pertama Penalaan Parameter PID

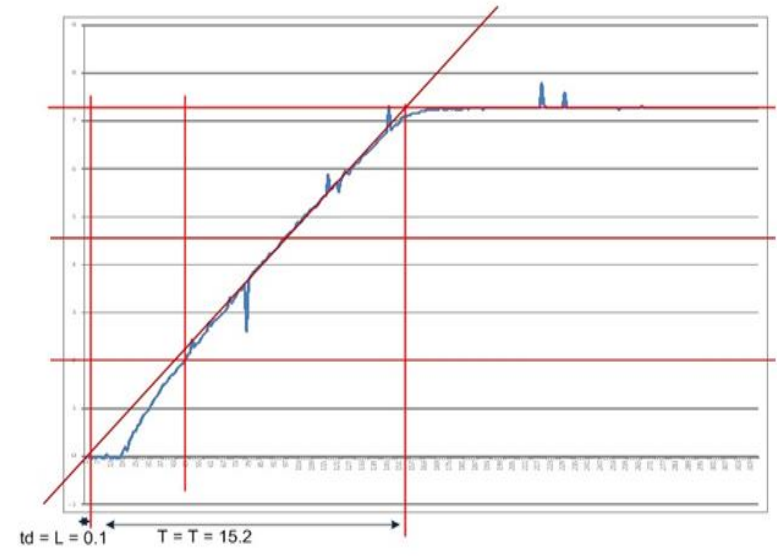

Gambar 7. Grafik Penalaan Tuning PID ke-1

Percobaan ini dilakukan dengan menggunakan nilai $\mathrm{Kp}=1$ pada saat pengujian alat untuk mendapatkan respon sistem[1].

$\mathrm{L}=0.1 ; \mathrm{T}=15.2$

$\mathrm{Kp}=1.2 \times \mathrm{T} / \mathrm{L}=1.2 \times 15.2 / 0.1=182.4$

$\mathrm{Ti}=2 \times \mathrm{L}=2 \times 0.1=0.2$

$\mathrm{Td}=0.5 \times \mathrm{L}=0.5 \times 0.1=0.05$

$\mathrm{Ki}=\mathrm{Kp} / \mathrm{Ti}=182.4 / 0.2=912$

$\mathrm{Kd}=\mathrm{Kp} \times \mathrm{Td}=182.4 \times 0.05=9.12$

b. Percobaan Kedua Penalaan Parameter PID

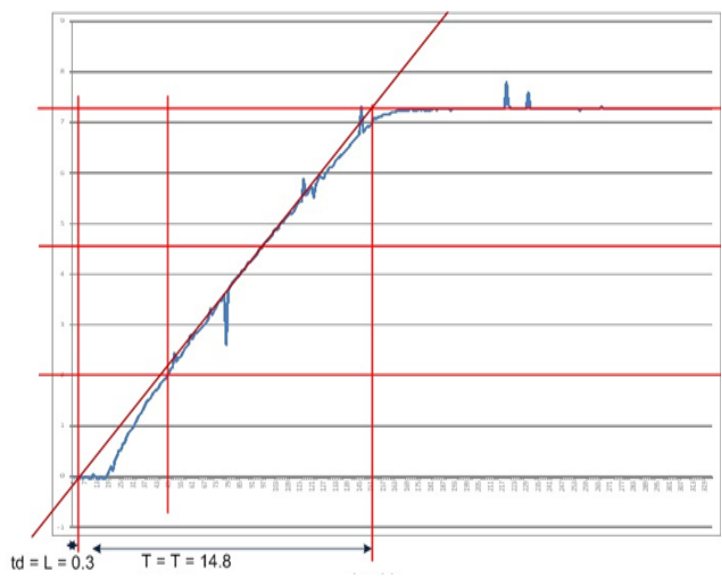

Gambar 8. Grafik Penalaan Tunning PID ke-2

$\mathrm{L}=0.3 ; \mathrm{T}=14.8$

$\mathrm{Kp}=1.2 \times \mathrm{T} / \mathrm{L}=1.214 .8 / 0.3=59.2$

$\mathrm{Ti}=2 \times \mathrm{L}=2 \times 0.3=0.6$

$\mathrm{Td}=0.5 \times \mathrm{L}=0.5 \times 0.3=0.15$

$\mathrm{Ki}=\mathrm{Kp} / \mathrm{Ti}=59.2 / 0.6=98.67$

$$
\mathrm{Kd}=\mathrm{Kp} \times \mathrm{Td}=59.2 \times 0.15=8.88
$$

Setelah dicobakan dalam program percobaan kedua yang mendapat respon lebih baik yang dapat menunjukan proses yang konstan. Sehingga memakai pendekatan Ziegler-Nichols untuk perancangan kontroler PID percobaan kedua.

\section{Pengujian Respon Sistem Tanpa Gangguan}

Pengujian Respon Sistem Tanpa Gangguan dengan memberikan variasi nilai Setpoint pada level ketinggian Air dalam tangki dengan kondisi Kran Air Tertutup. dengan menggunakan parameter PID sebelumnya yaitu sebesar $\mathrm{Kp}=59,2 ; \mathrm{Ki}=98,67$; dan $\mathrm{Kd}=8,88$. Respon sistem Kontrol PID Tanpa Gangguan ditunjukan pada gambar dibawah ini.

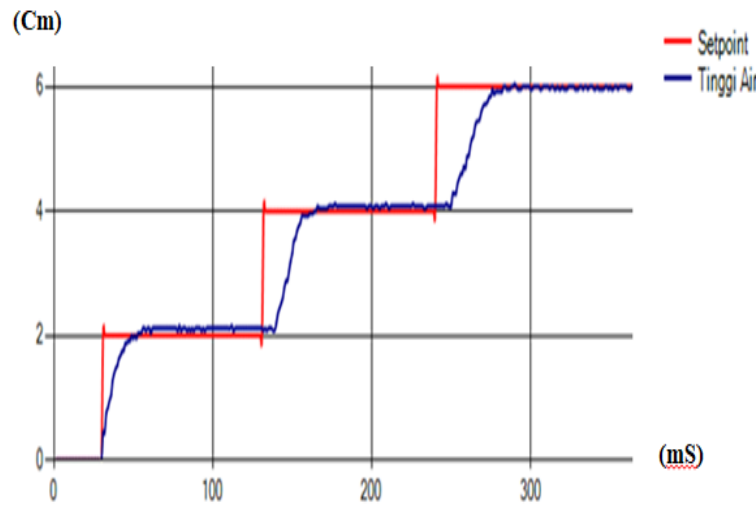

Gambar 9. Respon sistem Tanpa Gangguan

Gambar diatas adalah gabungan dari beberapa nilai setpoint yang dapat terjadi pada alat karena pergantian nilai setpoint dilakukan sesuai kebutuhan. Pada gambar diatas terlihat nilai setpoint yang diubah yaitu dari $2 \mathrm{~cm}$ ke $4 \mathrm{~cm}$ dan lanjut pada $6 \mathrm{~cm}$. berikut adalah analisa respon sistem waktu yang dihasilkan.

Tabel 2. Analisa Waktu Sistem

\begin{tabular}{|c|c|c|c|c|}
\hline Setpoint & $\begin{array}{c}\text { Time } \\
\text { Delay } \\
\text { (TD) }\end{array}$ & $\begin{array}{c}\text { Time } \\
\text { Rise } \\
\text { (TR) }\end{array}$ & $\begin{array}{c}\text { Time } \\
\text { Settling } \\
\text { (TS) }\end{array}$ & Error(\%) \\
\hline $2 \mathrm{Cm}$ & $0,6 \mathrm{~s}$ & $1,2 \mathrm{~s}$ & $1,8 \mathrm{~s}$ & 0 \\
\hline $4 \mathrm{Cm}$ & $0,9 \mathrm{~s}$ & $1,2 \mathrm{~s}$ & $3 \mathrm{~s}$ & 0 \\
\hline $6 \mathrm{Cm}$ & $1,2 \mathrm{~s}$ & $1,5 \mathrm{~s}$ & $3,3 \mathrm{~s}$ & 0 \\
\hline
\end{tabular}

\section{Pengujian Respon Sistem dengan gangguan} buka kran

Pengujian Respon Sistem dengan Gangguan dilakukan dengan memberikan variasi nilai Setpoint pada level ketinggian cairan dalam tangki dengan kondisi kran air dibuka. Pengujian ini dilakukan dengan membuka Kran pada saat sistem sudah 
stabil pada nilai setpoint $4 \mathrm{~cm}$, yang mengalami penurunan sebesar 0,4 cm selama 2,4 detik. Berikut dalah grafik respon sstem dengan gangguan buka kran.

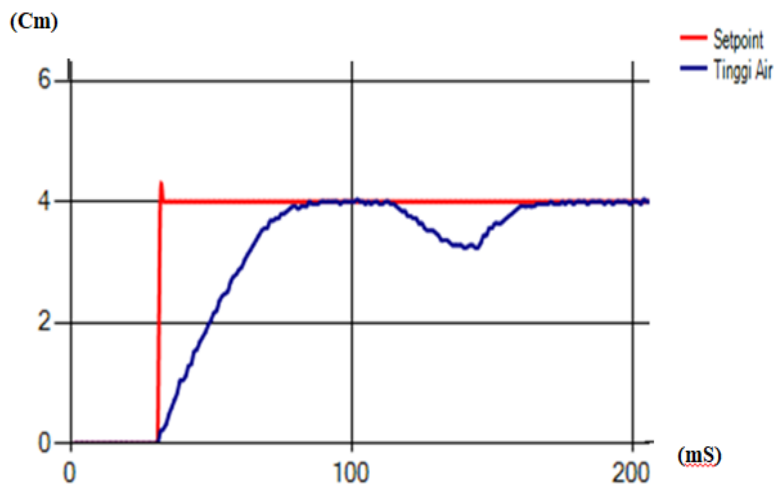

Gambar 11. Respon Sistem dengan Gangguan

\section{PENUTUP}

Penalaan Kendali PID menggunakan Metode Ziegler-Nichols tipe-1 bekerja dengan sangat baik untuk menstabilkan keadaan. Melalui dua kali percobaan eksperimen akhirnya mendapatkan nilai parameter PID yang stabil sebesar $\mathrm{Kp}=59,2 ; \mathrm{Ki}=98,67 ; \mathrm{Kd}=8,88$. Dengan menggunakan metode ini sangat mudah diaplikasikan untuk pengguna yang ingin mengendalikan plant dengan menggunakan kendali PID tetapi tidak memahami rumus matematis PID maka dapat menggunakan metode ZieglerNichols dengan menggunakan percobaan secara eksperimen untuk mendapatkan nilai stabil dengan aturan yang diberikan.

\section{REFERENSI}

[1] Jamal, Zaidir. Implementasi Kendali PID Penalaan Ziegler-Nichols Menggunakan Mikrokontroler. 2015.

[2] Nughroho, A.S., Fardidah, \& Suryopratomo, K. Rancang Bangun Sensor Pengukur Level Interface Air dan Minyak pada Mini Plant Separator. TEKNOFISIKA, Vol.2 N0.2, 42-54. 2013.
[3] Megido, A., \& Ariyanto, E. Sistem Kontrol Suhu Air Menggunakan Pengendali PID dan Volume pada Tangki Pemanas Air Berbasis Arduino Uno. Gema Teknologi VOL.8 NO.4, 21-28. 2016.

[4] Ikhsan, T. N. Sistem Monitoring Level Air Menggunakan Kendali PID. 2011.

[5] Nakhoda, Ismail, Y., \& Rizky, H. Sistem Kontrol Level Ketinggian Air pada Tando Menggunakan SMS Berbasis Smart Relay. Prosiding SENTIA, pp, 82-85. 2009.

[6] Prasetyo, J., Purwanto, \& Rahmadwati. Uji Performansi pada Sistem Kontrol Level Air dengan Variasi Beban Menggunakan Kontroler PID. 1-5. 2016.

[7] Saputra, U. E., Siswanto, \& Anif, M. Aplikasi Monitoring Pengisian Tengki Minyak Kelapa Sawit Dengan Sensor Ultrasonik SeedStudio SEN136B5B. BIT VOL 9 NO 2, 18. 2012.

[8] Nugroho, E. A. Pengontrolam Level Air pada Tangki Berbasis LabVIEW Terintegrasi dengan Arduino. Elektra, VOL. 1 NO.2, 32-41. 2016.

[9] Tahir, A. Otomatisasi Pengisian Tangki Air dengan Visualisasi Menggunakan Pemograman Visual Basic. Jurnal Ilmiah Media Processor Vol. 10 No.1, 330-338. 2015.

[10] Syahreza, S. Rancang Bangun Pengendali Otomatik Ketinggian Fluida dan Temperatur Menggunakan Programmable Logic Controller (PLC). Jurnal Rekayasa Elektrika Vol. 9, No. 1, 36. 2010.

\section{Biodata Penulis}

Tari Pujiati, lahir di Padang, 14 Mei 1998. Sarjana Sains Terapan, di jurusan Teknik Elektro Program Studi DIV Teknik Elektro Indusri, Fakultas Teknik, Universitas Negeri Padang.

Risfendra, S.Pd, M.T, Ph.D lahir di Riau, 13 Februari 1979. Sarjana Teknik Elektronika di Universitas Negeri Padang, lulus tahun 2004, S2 Teknik Sistem Pengaturan ITS tahun 2008. S3 Shouten Taiwan University of Science and Technology, Taiwan tahun 2017. Staf pengajar pada jurusan Teknik Elektro FT UNP sejak tahun 2005 sekarang. 